\title{
Short-term variability of solar wind number density, speed and dynamic pressure as a function of the interplanetary magnetic field components: A survey over two solar cycles
}

Article

Published Version

Bowe, G. A., Hapgood, M. A., Lockwood, M. and Willis, D. M. (1990) Short-term variability of solar wind number density, speed and dynamic pressure as a function of the interplanetary magnetic field components: A survey over two solar cycles. Geophysical Research Letters, 17 (11). pp. 18251828. ISSN 00948276 doi:

https://doi.org/10.1029/GL017i011p01825 Available at https://centaur.reading.ac.uk/38856/

It is advisable to refer to the publisher's version if you intend to cite from the work. See Guidance on citing.

Published version at: http://dx.doi.org/10.1029/GL017i011p01825

To link to this article DOI: http://dx.doi.org/10.1029/GL017i011p01825

All outputs in CentAUR are protected by Intellectual Property Rights law, including copyright law. Copyright and IPR is retained by the creators or other copyright holders. Terms and conditions for use of this material are defined in 
the End User Agreement.

www.reading.ac.uk/centaur

\section{CentAUR}

Central Archive at the University of Reading

Reading's research outputs online 


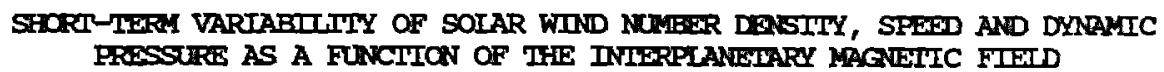
COMPONENIS: A SURVEY OVER TWO SOLAR CYCLES

G. A. Bowe, M. A. Hapgood, M. Iockwood and D. M. Willis

World Data Centre CI for STP, Putherford Appleton Iabaratory, UK

\begin{abstract}
2bstract. The variability of hamly values of volar wind number censity, nuber density veriation, speed, speed variation and dymamic presanre with IMF $\mathrm{B}_{2}$ and magnitude $|B|$ has been werined for the period 1965-1986. We wish to draw attertion to a strong correlation in nuber dersity and nuber density fluctuation with IMF $\mathbf{B}_{\mathbf{2}}$ charecterised by a symatric increasing trend in these quantities away from $\mathrm{B}_{2}=0 \mathrm{rrT}$. The fluctation level in solar wind speed is found to be relatively independent of $\mathrm{B}_{2}$. We infer that nuber density and nuber density variability deminate in controlling solar wind dynamic pressure and dymanic pressure variability. It is uso found that dynamic pressure is correlated with each copoment of MIF and that there is evidence of monhological differences between the variation with each co:panent. Finally, we examine the variation of nuber density, speed, dymanic pressure and fluctuation level in nuber density and speed with INF magitude $|B|$. Again we find that nuber density variation dominates over solar vind speed in controlling dymamic pressure.
\end{abstract}

\section{Introduction}

The $\mathrm{B}_{2}$ component of the interplanetary magnetic field (DFi), wich is parallel to the $z$-anis in GSI (ceocentric-solar-agnetospheric) coordinates, is ipportant as it is often used to assess the livelihood of magnetic recomection of the $\mathrm{DF}$ vith the terrestrial agnetic field. It is believed that recomection at the subsolar agnetopause is favoured at times when the DF is direted southward $\left(\mathrm{B}_{2}<0\right)$. The dependence of truns-polar valtage on $\mathrm{B}_{2}$ (see revieus by cowley, 1964; Reiff and Iutmam, 1986) is one primary piece of evidence sugporting the belief that whotic recomection is the dominant mananisa orr driving convective flows in the magnetosphere and ianosphere, as originally picoposed by Dungey (1061). Magnetic recomection is thought to coam in aither a "quasi-steady" marner or in transient buste known as "flux transfer events" (Fins). wase events have been evoked to explain and predict suller-scale ionospheric flow vartices treang compling of the dayside auraral ianosphene with the magnetcpause (eg. Iockwood et al., 1989). However, it has also been noted that FIRs alcne ave not sufficient to explain all the cbeerved Is ratures of vatioal flow and that scme, but not ai. events mey have been induced by solar wind branic peroure changes - even at tives of natumed IF (Ferrugia et al., 1999; sibedk et 4., 1909) . A thecretical eaplaration of how

Coprright 1990 by the Merican Geophysteal Union.

Paper number 906L01519

009-276/90/90GL-01519\$03.00 dynamic pressure changes prochuce flow signatures in the aurroral ionosphere has been provided by Southrood and Kivelsan (1990), who show that antisumard motion of closed field lines ("visoouslike" mantum transfer across the magnetopause) can be caused by the "buffeting" effect on the magnetosphere of changes in solar wind dyraic pecessure, as originaliy suggested by Dessler (1964) - Iockwood et al. (1990) have indicated that solar wind dynamic pressure variability would be expected to be the saine for northward and southard IMF. This would appear to linit the contribution that this coupling mechanism can wake to the total trans-palar valtage, to below the peak value of " $30 \mathrm{kV}$ observed curing northrard IPF. This inference is true provided that the magnetosphere does not alter in focm in scase marmer, such that its rexponse to solar wind dynamic pressure changes is greater for southmantdirected MF. This paper examines the relationship between solar wind dymamic pressure and the IIP, and in particular B. It also considers the factors that control dynaic pressure and its variability on time-scales of 0.1 - 1 hour.

\section{Analysis of the Solar Wind Dataect}

The anItape version 4 from Nssoc was used as the data somce for the analysis. It is recognised that this is an inhomgeneous dataset; containing data from ene than 10 spacecraft (eg- Mip-8, ISEE-3, VRIA) at a variety of locations, and covering a period of 25 years (1963-87). A total of 60226 hourly values of solar wind ion n-ber density $n$, standard deviation in nuber onsity $\sigma_{n}$, speed $v$, standard deviation in speed $\alpha_{v}$, and IMF coponentes $B, B$ and $B$ (all three in GSY coordinates), ware available in the dataset. The following parametens were also derived fran those ifsted above; dynamic pressure $P_{d}=\mathbf{m} . n . v^{2}$ (where II was assuard equal to one proton mass), Inir magnitade $|B|$. fractional fluctution in niber density, $a_{n} / n$, and fractional fluctartion in speed, $\sigma_{v} / v$. In ondar to exrmine the variation of one parameter, $Y$, with arother, $X$, the data vere sarted by the value of $X$. Data points which did not fall in the extrea wings of the distribution of $x$, were then averaged in 118 'imer' bins of 500 data points $(X, Y)$ per bin $(* 0.83$ * of the total datapet per bin). The rwining 1226 data points, reprenting the wings of the divtribution of $x$, were divided into 2 'atter bins of 613 data pairs in each $(* 1.02$ of the total cataent per bined data paint). The total nuber of binmed data points $(\infty, \infty)$ ) was the 120. Tuis binning procedure ensures that all dispiayed chta polnts In the figures are an averag of a large (2500) n-ber of bourly values. The entect of varying the nuber of data point par bin wa investoted for

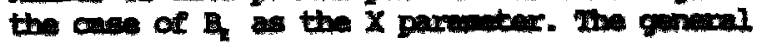



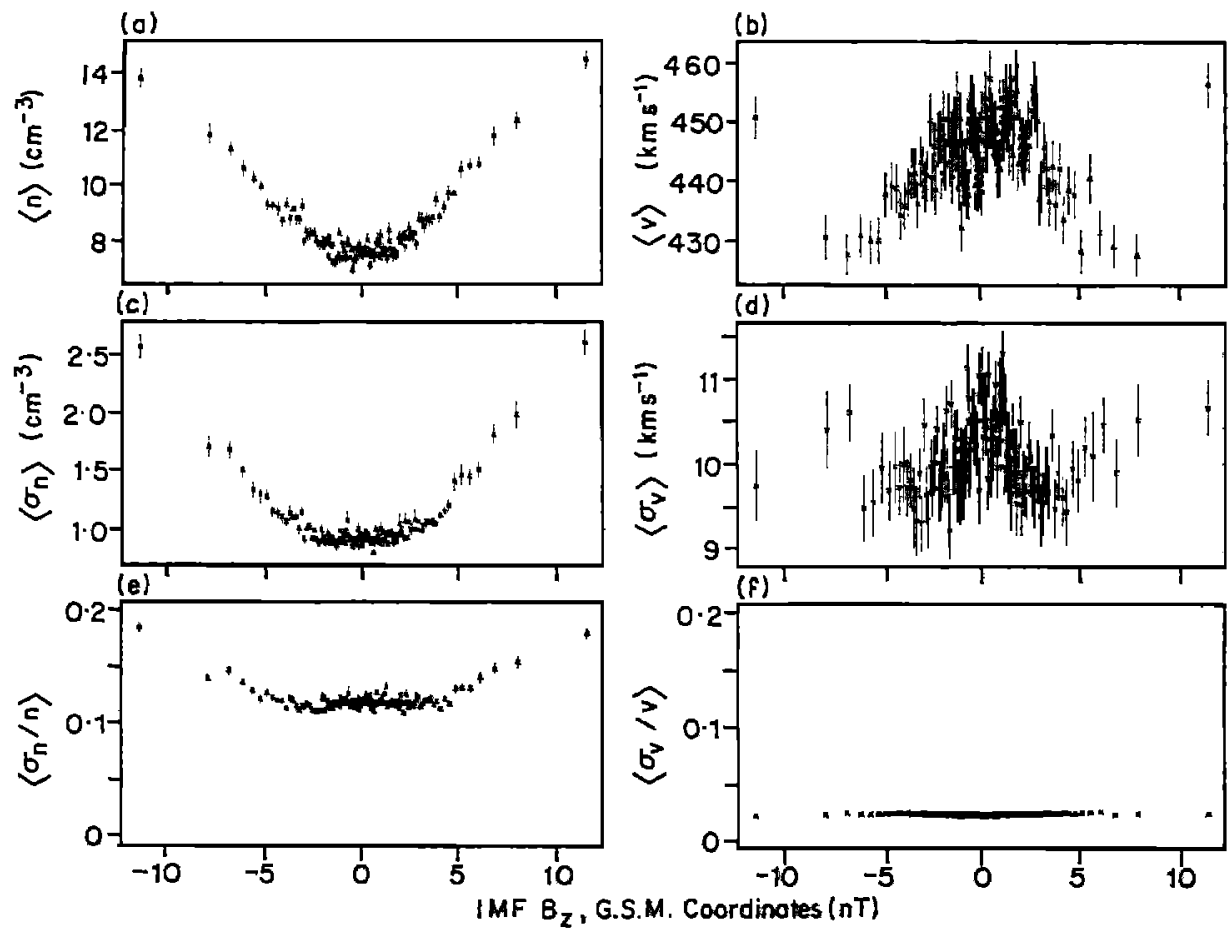

Fig. 1. Means of (a) ion rumber density \langle\rangle , (b) solar wind speed $\langle v\rangle$, (c) number density variation $\left\langle\sigma_{n}\right\rangle$, (d) speed variation $\left\langle\sigma_{y}\right\rangle$, (e) fractional number density variation $\left\langle\sigma_{n} / n\right\rangle$, and (f) fractional speed variation $\left\langle\sigma_{v} / v\right\rangle$ plotted ageinst IMF $B_{2}$.

trends reported here were always observed. The standard errors of the means of $X$ and $Y$ were also calculated, and all error bars shom in the figures represent deviations from the mean of \pm 1 standard error. The number of samples per hour used in calculating $n, v, \sigma_{n}$ and $\sigma_{y}$ is very variable $(-6-120)$ deperding on the spacecraft used as the data-source. To examine the effects of inhoingreneity in the data source (due to different sampling rates and spacecraft location), the analysis was performed for the pairs of years 1968-69 (principally ATMP-1 and -2 , INP-4 and -5 and HEOS-1 and -2) , 1978-79 (approximately halfand-half frum TMP-8 and ISER-3), 1975-76 and 1985-86 (both periods vitually all IIP-8 data). Despite the variation in data source, the same trends were found in the results for these chatasubsets as for the whole dataset.

The analysis was also performed for 65 (geocentric-solar-ecliptic) cocrdinates, and again the same trends in the results were observed. In this paper we have used the colpanents of DF in the GSM coordinate system because they are mone relevant to studies of solar wind-magnetosphereionosphere coupling.

\section{Variation of $n$ and $v$ with $B_{2}$}

Figure 1 shows the results of the analysis for solar wind number density and speed as bimed values, sorted on IIF $\mathrm{R}_{2}$. From flgures 1(a), 1(c) and $I$ (e) it can be seen that these is a systematic syimaticic trend in mean nuber density, \langle\rangle , woan number density variation, $\left.\infty_{n}\right\rangle$, and mean frectional variation, $\infty_{n} / \omega_{i}$ all of which incree with $\left|\mathrm{B}_{2}\right|$. The corresponding variations for anlar wind speed, $v$, are shown in figures 1(b), $I$ (d) and $1(\mathrm{f})$. Sowe variation with $\mathrm{B}_{2}$ is evident, in partiallar for $\langle v\rangle$; however, the standard errors are relatively larger and the variation moch smaller than in the corresponding plots relating to mmber density. Average velocity $\left\langle\mathrm{v}\right.$, is generally lower at large $\left|\mathrm{B}_{2}\right|$ (where 40 is higher), except for the two 'outer' bins. The mean velocity variation $\left\langle\sigma_{v}\right\rangle$ shows a weak winim. at $\mathrm{B}_{2}=0 \mathrm{nT}$. Figure $I(f)$, when conpared with figure $1(e)$, reveals that the mean fractional variation in nuber density, $\left\langle\sigma_{n} / n\right\rangle$, is a tor of * 5 greater than that in velocity, $<\alpha_{\gamma} / N$, $\mathrm{B}_{2}=0 \mathrm{mr}$ increasing to $* 7.5$ at $\left|\mathrm{B}_{2}\right|=10 \mathrm{rr}$ because of the relatively small trend in $<0_{y} / p$ with $B_{z}$. We also note that $\left\langle\sigma_{n} / n\right\rangle$ is relatively constant for $\left|\mathrm{B}_{2}\right|<5 \mathrm{rr}$.

\section{Variation of $P_{d}$ with InF Couponents}

Pigemes 2(a), 2(b) and 2(c) show, respectivaly. the variation of mean dynamic peressure, $\left\langle\boldsymbol{P}_{d}\right\rangle$, wh each component of the IMP, $\mathrm{B}, \mathrm{B}$ and $\mathrm{B}$. Woch plot exhibits a general trend to higher presen with increasing field (irrespective of sign) though there are differences in the plots with regand to the behaviour of $\left\langle P_{d}\right\rangle$ around 0 rIr. If component $\mathrm{B}$ shows the widest spread in megneted field value and $\mathrm{B}_{x}$ shows the least. In ganeecal, all three plots reflect the fact that B tands to increase with dymanic peressure (at least tor larger B - eve figme 3 (c)) but note that $B$ is the only component for wich $P_{d}$ increas anst monotonically with the magnitude of the fleid component.

$$
\text { Variation of } n, v \text { and } P_{d} \text { with }|B|
$$

Fignes $3(a)$ through 3 (e) show, nempotivily the variation of $\alpha\rangle,\left\langle v,\left\langle P_{d}\right\rangle,\left\langle a_{n} / m\right.\right.$ and $4, /$ 


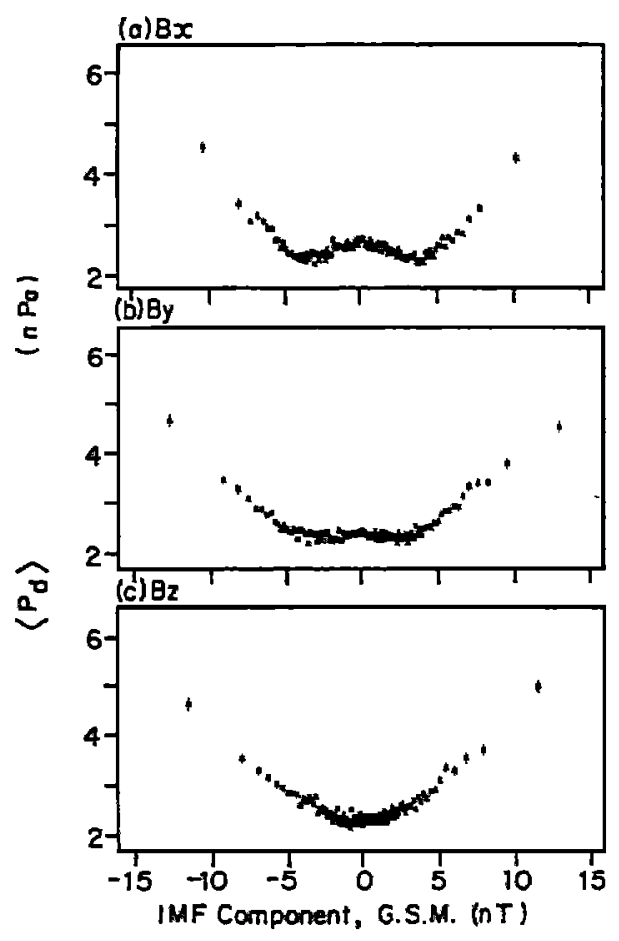

Fig. 2. Kan dynamic pressure $\left\langle P_{d}\right\rangle$ plotted gainst $I$ IF caponent (a) $\mathrm{B}_{x}$, (b) $\mathrm{B}_{1}$, and (c) $\mathrm{B}_{2}$.

vith DF magnitude $|B|$. Nean ian number density, (D), exhibits a minim at $|B| * 4 \pi T$ where mean speed, $\langle v\rangle$, shows a corresponding maximim; $\langle\psi\rangle$ also stows a flat minimm at $|\mathrm{B}|=9 \mathrm{nT}$ and its highest values at large $|B|$. The anticarrelation of as with $|B|$ for $|B|<4 \mathrm{IF}$ (corresponding to -25 t of the dataset) is consistent with the resents presented by Burlaga (1968), Vellante and Lamurs (1987), Roberts et al. (1987) and Roberts (1990). An interpectation of the antiocrrelation as being due to the presence of norpropagating tructures with internal peressume balance and a cheracteristic time scale of $<10$ hours was put conerd by Vellante and Iazarus. Roberts (1990) proposed that the "psenibsound" theory of intugery et al. (1987) may be a possible aplanation for the presence of these structures In the solar wind. Vellante and Iazarus also noted that there is a change, at larger time scales, to the positive correlation of $n$ with $|B|$ as reported by Dirlaga and Ogilvie (1970). We suggest turtatively that this may be responsible for the unmaround in the variation of or with $|B|$ in fingre 3(a). We do not, hovever, offer these revits as evidence of positive correlation af $n$ vith $|B|$ at larger time scales. Although the wores are of hourly values, parsistently high vilues of $n$ and $|B|$ over pariods of several hours doit lead to positive correlation being evident In the man of hourly values. Indeed, dotailed - ination of a linited nuber of high $|B|$, high n caeas has shown that arch conditions can provail owe time-ales as lang as 20 hours. Futhemore, in man cases, these canditions were fallowed by puried of enhanced solar wind speed. The positive oxralation is due largaly to the grouth for thing up") of the interiaction regions of fast bine vind stremis (Burleg and Oglivie, 1970). wile vould be constetent with the positive correlation of $\mathrm{c}\rangle$ with $|\mathrm{B}|$ in figure $3(\mathrm{a})$, ocarring for high $|B|$, and with the associated high mean solar wind speed, $\langle v\rangle$, of figure $3(b)$. Hean dymamic pressure, $\left\langle\mathrm{P}_{\mathrm{d}}\right\rangle$, and mean nuber density fractional variability, $\infty_{n} / n>$ show the same general behaviour as \langle\rangle with a minime at $|B|=4 \mathrm{nT}$. The fractional variability in speed, $\langle 0, N>$, is lover than that in nuber density by a factor 4 at $|B|=4 \mathrm{rT}$ and $\sim 8$ at $|B|=19 \mathrm{nT}$. Again this suggests that rumber density dowinates over speed in controlling solar wind dyrate pressure.
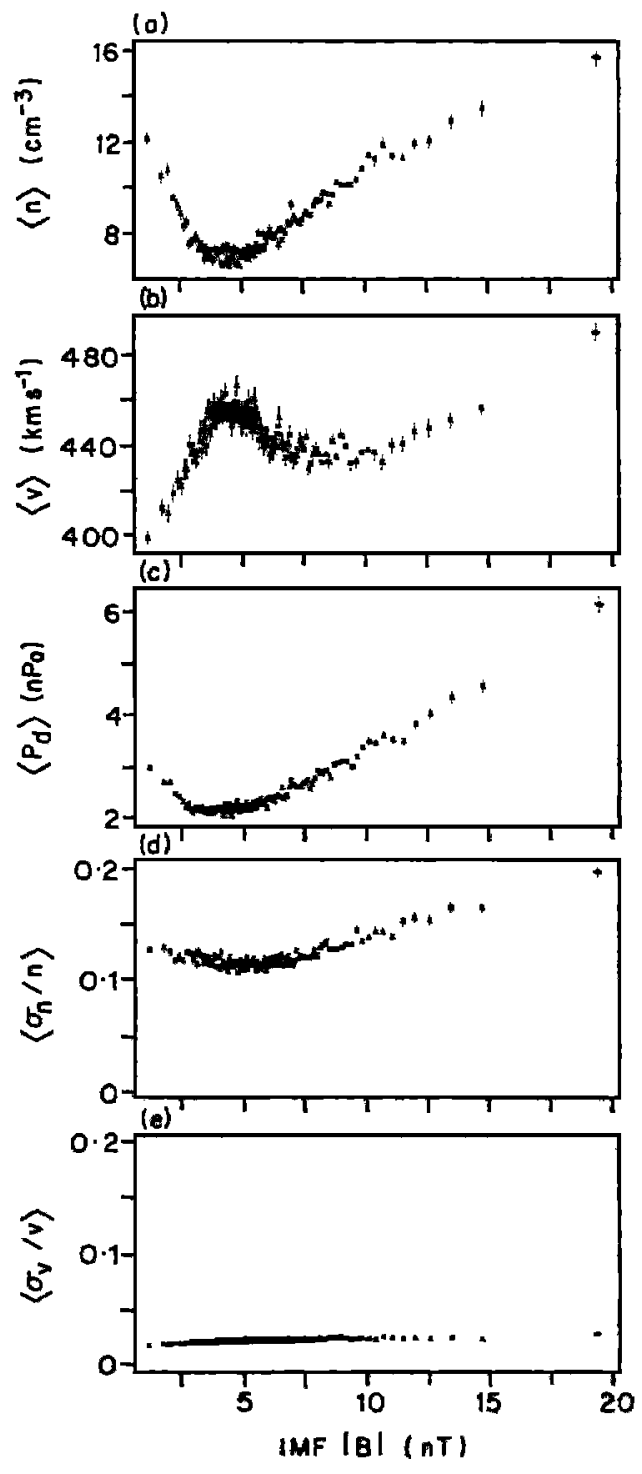

Fig. 3. Nans of (a) ion nuber density $n$, (b) solar wind apeed $<>$, , (c) solar wind dynaic pressure $\left\langle P_{d}\right\rangle$, (d) fractional nuber dansity varlation $\left\langle\mathrm{O}_{n} / \mathrm{n}\right\rangle$, and (e) frectional speed variation $\omega_{v} / D$ against $I$ iF agnitude $|B|$.

\section{Canalusions}

The revits presented in this peper are largely of a phencmelogtoal nature - we have not sought hare to erplain the aystemtio trends thet wo ha

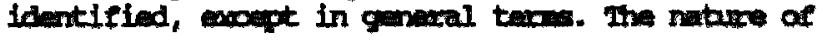


the analysis is such that short-term ( $<1$ hour) variability alone has been investigated directly. We speculate that large scale features in the solar wind such as stream interaction regions and perhaps "flux-bubbles" fran corcnal mass ejections (for example see review by Holzer, 1979) may be responsible for the enhancement in dynamic pressure at larger than average values of DMF and curing periods when the IMF has a large out-ofecliptic component. An analysis of 10 major magnetic starns, which occured during 1978/1979 and which were associated with laxge southward $B_{2}$, led Tsurutani et al. (1990) to attribute nine of the ten to interplanetary shocks and the remaining one to a non-coupressional density enhancement. The averages of solar wind number density, number density fluctuation level and dynamic pressure have all been shown to increase systematically with $\left|B_{2}\right|$ and symmetrically about $B_{2}=0 \mathrm{nT}$; i.e. there is no difference between northward and southward IMF orientation. Because solar wind mean speed and its mean variability are found to be relatively indeperdent of $B$, we infer that the fractional variability or "buffeting level" of dynamic pressure (i.e. $\left\langle\sigma_{\mathrm{pd}} / \mathrm{P}_{d}\right\rangle$ ), on a time scale of $-0.1-1$ hour, will increase with $\left|\mathrm{B}_{2}\right|$. reflecting the variation in $\left\langle\sigma_{n} / n\right\rangle$. We conclude that buffeting of the magnetopause by dynamic pressure variability could, in theory, influence the cbserved anti-correlation of trans-polar voltage with $B_{2}$ when $B_{2}<0$. However, in order to postulate that increased buffeting contributes significantly to the additional transpolar voltage that is cbserved when the DMF is directed southward (the voltage usually being ascribed to the effects of subsolar magnetic recomection), sone viable explanation must be supplied to acoount for the fact that this does not ocour when the IMF is directed northward.

Acknowledgements. The authors are grateful to the marry experimental groups who contributed to the anItape dataset. In recognition of the large fraction of these data fran the MIP-8 spacecraft, we would particularly like to thank R. P. Iepping of Goddard SFC and A. J. Iazarus of MIT. Thaniks also go to J. H. King of NSSDC for the assembly and provision of the aurltape dataset, to A. J. Iazanus and R. A. Harrison for discussions of the work, and to B. J. Read for providing the relational database managenent systen used in the analysis.

\section{References}

Burlaga, L. F., Micro-scale structures in the interplanetary mediua, sol. Prys., 4, 67, 1968.

Burlaga, L. F. , and K. W. Ogilvie, vagnetic and thermal pressures in the solar wind, Sol. Prys., 15, 61, 1970.

cowley, S. W. H., Solar wind control of magnetospheric carvection, in "Achievents of the

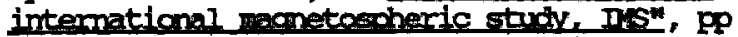
483-494, ESA SP-217, ESIEC, Nocturijk, The Netherlands, 1984.

Dessler, A. J., Length of the magnetaspheric tail, J. Ceavors, Res, 69, 3913, 1964.
Dungey, J. พ., Interplanetary magnetic field and the auroral zones, Phys. Rev. Lett., 6, 47, 1961.

Farnugia, C. J., M. P. Freman, S. W. H. Covley, D. J. Southwood, M. Lockwood, and A. Etenedi, Pressure-driven magnetopause motions and attendant response on the ground, planet. Sma Sci., 37, 589, 1989.

Holzer, T. E., The solar wind and related astrophysical phencmena, in msolar systren plasma physics, vol. 1", ed. C. F. Remel, I. J. Ianzerotti, and E. N. Parker, pp 101-176, North-folland, Amsterdam, 1979.

Lockwood, M., P. E. Sandholt, S. W. H. Cowley, and T. Oguti, Interplanetary magnetic field combal of dayside auroral activity and the transfer of momentim across the dayside magnetopause, Planet. Space Sci., 37, 1347, 1989.

Iockwood, M., S. W. H. Cowley, P. E. Sancholt, and R. P. Iepping, The icospheric signatures of flux transfer events and solar wind dymic pressure changes, submitted to J. Gecoinys. Res., 1990.

Mortgomery, D., M. Brown, and W. H. Natthess, Density fluctuation spectra in magnetohydrodynamic turbulence, I. Ceonhs. Res., 92, 282, 1987.

Reiff, P. H., and J. G. Iutham, solar wind control of the polar cap voltage, in usolar wind-racmetosphere coupling", ed. Y. Kanide and J. A. Slavin, pp 453-476, Terra scientifica, Tokyo, 1986.

Roberts, D. A., Heliocentric distance and terpecal dependence of the interplanetary densitymagnetic field magitude correlation, I. Ceaphys. Res., 95, 1097, 1990.

Robents, D. A., L. W. Klein, M. I. Goldstein, and W. H. Mattheus, The natrre and evolution of magnetohytrodymaic fluctuations in the solar wind: Voyager observations, J. Geachve. Pas, 92, 11,021, 1987.

Sibeck D. G., W. Baumjoham, and R. E. Iopes, Solar wind dynamic variations and transient magnetospheric signatires, Ceophvs. Res, Ietta 16, 13, 1989.

Southmood, D. J., and M. Kivelson, I. Ceadru. Res, in press, 1990.

Tsurutani, B. T., B. E. Goldstein, E. J. Sith, a D. Gonealez, S. I. Akasofu and R. R. Ardeusen, The interplanetary and solar causes of gecmagnetic activity, planet. Space Scil, $\mathbf{1}$. 109, 1990.

Vellante, 4. , and A. J. Iazanus, An analysis $\alpha$ solar wind fluctuations between 1 and $10 \mathrm{~m}$, J.Geochys. Res, 92, 9893, 1987.

G. A. BOWe, M. A. Hapgood, M. Lockwood and D. M. Willis, World Data Centre Cl for SIP, Rutherford Appleton Iaboratory, Chilton, Dídoot. oxan, $\operatorname{coll} \operatorname{oox}$, UK.

(Received April 9, 1990, revised May 18, 1990: acoepted July 3, 1990.) 